
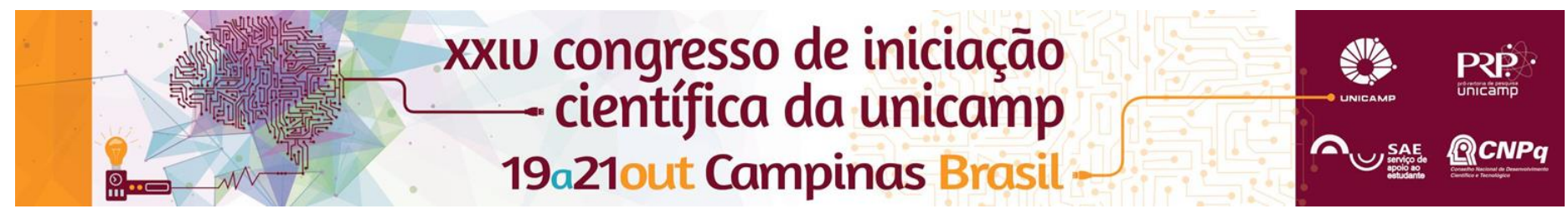

\title{
Influência da injeção de toxina botulínica tipo A nos músculos da mastigação sobre a eficiência mastigatória e dor em portadores de DTM miogênica com dor crônica.
}

\section{Andréia M. Makyama*, Giancarlo De la Torre Canales, Célia M. R. Barbosa, Natalia A. Pinzon, Alfonso A. Sanchez.}

\section{Resumo}

O objetivo do experimento será comparar a influência da Toxina Botulínica na DTM com dor crônica, em relação à aplicação de soro fisiológico nos músculos temporais anteriores e masseteres. Participarão 40 voluntárias divididas aleatoriamente em dois grupos. As variáveis dependentes serão mensuração da intensidade da dor pela Escala Visual Analógica, análise do limiar de dor à pressão pela algometria e análise da eficiência mastigatória.

\section{Palavras-chave:}

Disfunção temporomandibular, toxina botulínica, dor crônica Introdução

A DTM apresenta sinais clínicos e sintomas objetivos de fácil identificação, como os ruídos articulares, hiper ou hipomobilidade mandibular, irregularidades e/ou assimetria nos movimentos de abertura e fechamento bucal, cefaleias secundarias, mastigação deficiente, e distúrbios de deglutição e fala.

Estudos sugerem que $40 \%$ a $60 \%$ dos indivíduos na população em geral apresentam algum tipo de DTM, sendo que há maior prevalência da disfunção em mulheres na faixa etária de 18 a 45 anos, devido a fatores emocionais anatômicos e mudanças hormonais.

As terapias conservadoras estão indicadas como tratamento de eleição. Dentre estas, citam-se agentes farmacológicos, automassagem, terapia física, educação do paciente, autocuidados. Hoje em dia, aplicações de toxina botulínica (BoNT-A) nas áreas sensíveis da face e mandíbula têm sido utilizadas com relativo sucesso na remissão da sintomatologia dolorosa crônica ligada à DTM. Esta age temporariamente como promotor de analgesia via relaxamento da fibra muscular inflamada, bloqueando a liberação da acetilcolina (ACh) nas junções neuromusculares.

Assim o objetivo do trabalho é avaliar a eficácia da toxina BoNT-A na disfunção temporomandibular miogênica.

\section{Resultados e Discussão}
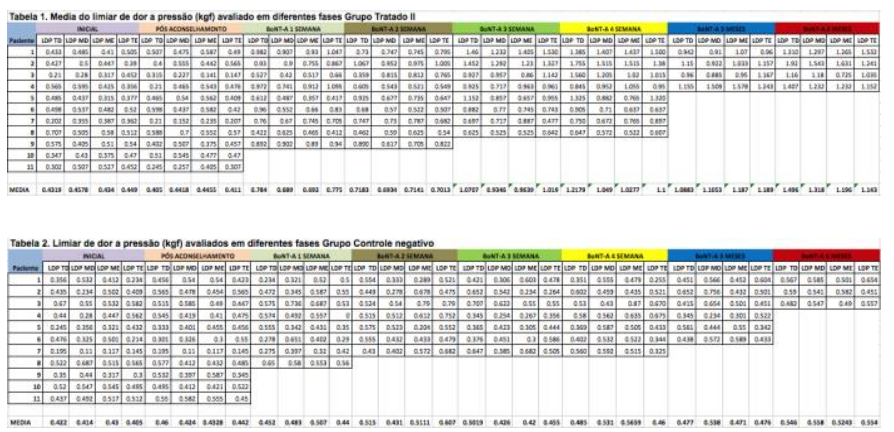

Apesar de não contar ainda com a totalidade de voluntárias requeridas para cada grupo e de não contar com a estatística dos dados devido ao fato de as voluntárias se encontrarem ainda em fase de avaliação, podemos notar que existe uma tendência a que o grupo tratado com toxina botulínica tenham valores mais altos no limiar de dor a pressão medido através do teste de algometria quando comparados com o grupo controle negativo, o que poderia significar que o limiar de dor a pressão das voluntarias melhorou após aplicado o tratamento com toxina botulínica.
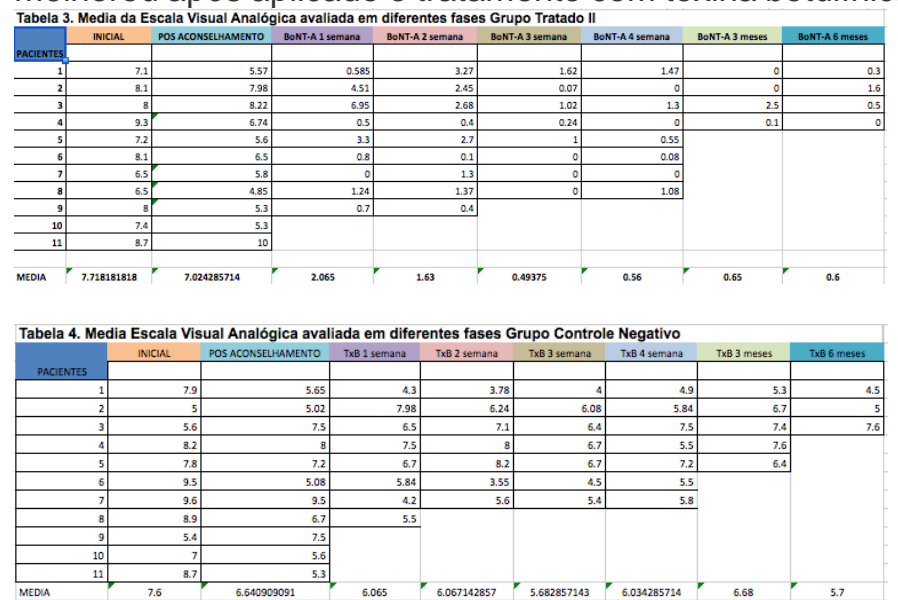

Apesar de não contar ainda com a totalidade de voluntárias requeridas para cada grupo e de não contar com a estatística dos dados devido ao fato de as voluntárias se encontrarem ainda em fase de avaliação, podemos notar que existe uma tendência a que no grupo tratado com toxina botulínica os valores da dor subjetiva relatada pelo paciente avaliada através da Escala Visual Analógica diminuíram em cada uma das avaliações e quando comparados esses valores com os do grupo controle negativo, existe também uma tendência a que esses valores sejam menores nos grupos tratados

\section{Conclusão}

A toxina botulínica tipo A apresenta-se como uma alternativa terapêutica para pacientes portadores da disfunção temporomandibular miogênica.

\section{FAPESP: 2014/158637}

\section{Agradecimentos}

Clark GT. The management of oromandibular motor disorders and facial spasms with injections of botulinum toxin. Phys Med Rehabil Clin N Am 2003 Nov:14(4): 727-48.

Dressler D, Saberi FA, Barbosa ER. Botulinum Toxin - Mechanisms of action. J Arq Neuropsiquiatr. 2005; 63 (1): 180-185.

Okeson JP. Orofacial Pain-guidelines for assessment, diagnosis, and managementThe American Academy of Orofacial Pain. Carol Stream: Quintessence Publ Co. 1996, $285 p$.

Okeson JP. Dores bucofaciais de Bell. 5 Ed. São Paulo: Quintessence, 1998. 500p 
DOI: 10.19146/pibic-2016-51183 